\title{
Valve-sparing repair to alleviate pulmonary regurgitation may lead to as much right ventricular dilatation as a transannular patch: A catch-22?
}

\author{
Tae-Jin Yun, MD, PhD
}

From the Division of Pediatric Cardiac Surgery, Asan Medical Center, Seoul, Republic of Korea

Disclosures: Author has nothing to disclose with regard to commercial support.

Received for publication Sept 19, 2017; accepted for publication Sept 22, 2017; available ahead of print Oct 27, 2017.

Address for reprints: Tae-Jin Yun, MD, PhD, Division of Pediatric Cardiac Surgery, Asan Medical Center, 388-1

Poongnap-dong, Songpa-gu, Seoul, Republic of Korea (E-mail: tjyun@amc.seoul.kr).

J Thorac Cardiovasc Surg 2018;155:1174-5

0022-5223/\$36.00

Copyright (c) 2017 by The American Association for Thoracic Surgery

https://doi.org/10.1016/j.jtcvs.2017.09.116

It has become a cliché to state that placement of a transannular patch leads to a cascade of pulmonary regurgitation (PR), right ventricular dilatation, ventricular arrhythmia, and sudden death. Various surgical techniques have been proposed to alleviate PR by preserving the pulmonary valve (PV) itself or the PV annulus (PVA), hence the term valvesparing repair (VSR). In this issue of the Journal, Hofferberth and colleagues ${ }^{1}$ from Boston Children's Hospital report on how they tackled this issue by using a relatively new surgical technique, intraoperative balloon dilatation (IBD) of the PV, which appears feasible and sensible. They found, however, that IBD resulted in suboptimal

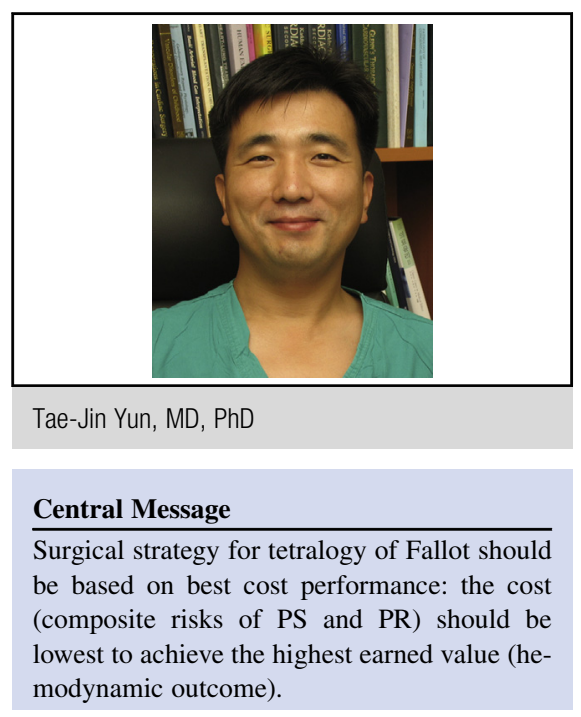

See Article page 1163.

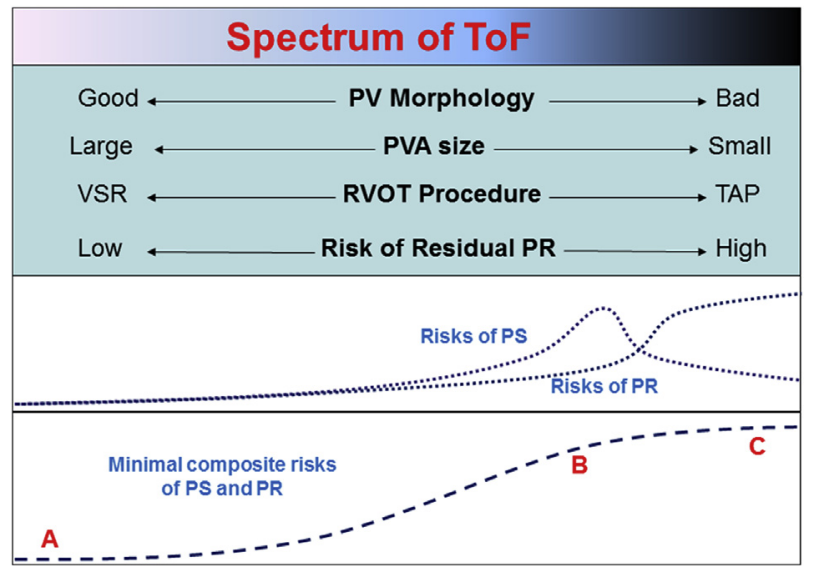

FIGURE 1. Tetralogy of Fallot as a spectrum of disease with varying severity. Point A represents patients with a large pulmonary valve annulus, who need minimal intervention on the pulmonary valve. Point B represents patients with a marginally small pulmonary valve annulus, for whom it is important to ascertain the balance between pulmonary stenosis and pulmonary regurgitation that results in the best hemodynamic outcome. Point $\mathrm{C}$ represents patients with a very small pulmonary valve annulus, for whom valve-sparing repair may result in unacceptably high cost. $T o F$, Tetralogy of fallot; $P V$, pulmonary valve; $P V A$, pulmonary valve annulus; $V S R$, valve sparing repair; RVOT, right ventricular outflow tract; TAP, transannular patch; $P R$, pulmonary regurgitation; $P S$, pulmonary stenosis. midterm outcomes in terms of the development of both significant PR and pulmonary stenosis (PS). Although the impact of these observations on their ensuing practice is uncertain, Hofferberth and colleagues ${ }^{1}$ are at least to be commended for their scrupulousness in reporting the inconvenient truth.

In the novel Catch-22 by Joseph Heller, ${ }^{2}$ captain John Yossarian, a US Army Air Forces B-25 bombardier, tried to steer clear of the deadly flight by asserting his insanity, which was the only accepted excuse for the pilots to be exempted from the mission (catch-22). His endeavor was in vain, however, because trying to prove his insanity for his own safety was deemed a logical reasoning process, or proof of sanity! Likewise, VSR for patients with a small PVA necessitates aggressive interventions on the PV (excessive ballooning of the PV) to minimize the risk of significant residual PS, which in turn jeopardizes the structural integrity of the PV and leads to what VSR is meant to prevent: PR!

We all agree on that ideal right ventricular outflow tract management is less PR and less PS, but how? In the spectrum of tetralogy of Fallot (Figure 1), determination of surgical strategy should be based on the best cost performance. The cost (composite risks of PS and PR) 
should be lowest to achieve the highest earned value (hemodynamic outcome). For instance, patients with a large PVA ( $A$ in Figure 1 ) need a minimal intervention on the $\mathrm{PV}$. If excessive ballooning is imposed on the PV, the cost (PR) gets extravagantly higher. For patients with a marginally small PVA ( $B$ in Figure 1 ), it is important is to ascertain the balance between PS and PR that results in the best hemodynamic outcome. Although it is unclear whether leaving $35-\mathrm{mm} \mathrm{Hg}$ right ventricular outflow tract gradients with grade I PR costs less than leaving $25-\mathrm{mm} \mathrm{Hg}$ gradients with grade II PR, there should be the ideal balance point somewhere in between. Fine adjustment of PS and PR may be very difficult with a blind procedure like IBD. In patients with a very small PVA ( $C$ in Figure 1), VSR with IBD (or whatever procedure would be used) may result in unacceptably high cost (PS).

Sooner or later, tissue-engineered autologous heart valves will be available for the initial repair of tetralogy of Fallot, which may render the debate on right ventricular outflow tract reconstruction obsolete. Until then, however, we are in dire need of healthy and candid discussion on what we are doing right and what we are doing wrong, just as the Boston group did with this study.

\section{References}

1. Hofferberth SC, Nathan M, Marx GR, Lu M, Sleeper L, Marshall AC, et al Valve-sparing repair with intraoperative balloon dilation in tetralogy of Fallot: midterm results and therapeutic implications. J Thorac Cardiovasc Surg. 2018; 155:1163-73

2. Heller J. Catch-22. New York: Simon \& Schuster; 1955. 